\title{
Mentoring Women Psychiatry Residents: Implications for Academic Leaders and Educators
}

\author{
Jennifer Ford
}

Received: 30 July 2014 / Accepted: 7 October 2014 / Published online: 11 November 2014

(C) Academic Psychiatry 2014

"I don't know how you do it all?!" This is an all too familiar question I get as a female psychiatry resident and mother of two small children. When I am asked this question, I always think that I have only done what most other women in my training program have done and that I am not unique. Yet, there is something very challenging about balancing the demands of so many different roles during training. In answering this question, I realize that I have benefitted greatly from watching my female mentors balance these multiple roles themselves, and it is mentoring that has most facilitated my academic and personal successes. However, I did not find my mentors until later in my residency training. In the third year, I met my first mentor who showed me that it was possible to publish scholarly work, be an effective clinician, and raise a family. In other words, she offered potential "solutions" to the work-life balance conundrum. My experience with mentoring has been so significant that it has inspired me to learn more about how to facilitate this important relationship for other female trainees in psychiatry.

As someone who is embarking on a career as a junior faculty member at an academic institution, it is disheartening to see the Association of American Medical Colleges' statistics showing that despite many years of gender parity in medical school enrolment (47.1\% of medical school students were female vs. $52.9 \%$ male in 2012), only $19 \%$ of full professors are female [1]. A recent qualitative study of women who left academic institutions confirmed that the difficulty with work-life balance was a factor in the decision to leave [2].

Since taking on the roles of both mother and resident, I have struggled with my own feelings of frustration over worklife balance pressures. The inevitable "trade-offs" often mean

J. Ford $(\bowtie)$

McMaster University, Hamilton, Ontario, Canada

e-mail: jennifer.ford@medportal.ca that I will miss out on something, such as last year when I could not attend a conference because I did not want to travel on a long flight with an infant and this year when I missed seeing my son take his first steps while I was on call.

Bogan and Safer discussed the work-life balance issues specific to women psychiatry trainees in a special issue of Academic Psychiatry devoted to women's professional development and offer reasons why these figure so prominently in a trainee's life. During residency, many women choose to have children, and work-family balance becomes especially salient. A female resident may have less flexibility to pursue scholarly activities outside of the training curriculum, activities that are not only enriching but also required for a position at an academic center. Many residents lack the financial resources to obtain outside help with childcare and other household needs and may therefore be required to devote more time to domestic activities after working hours [3]. More than 10 years after this special edition of Academic Psychiatry, these same challenges remain for women trainees, and my own experiences reflect this ongoing struggle.

I feel that I am proof that mentorship represents one possible way to assist female residents to overcome the many challenges that they face. Academic departments have begun to implement formal mentorship programs, as research has shown that tangible benefits can result from mentoring including increased research productivity and career advancement [4]. The benefits of mentorship and the challenges of being a woman in residency training make residency the ideal time to initiate a mentoring relationship. Despite its importance, a recent study by Buddeberg-Fischer et al. showed that female physicians were less likely to have a mentor than men (40.5 vs. $58.9 \%$ ) [5]. A mentorship needs survey of the psychiatry residents I conducted at McMaster University also showed that just $30 \%$ of the female residents had a mentor $(n=9 / 27)$, while $56 \%$ of males did $(n=5 / 9)$. Furthermore, even when women have mentors, they are more likely to be male due to a 
paucity of women at higher academic ranks. The likelihood of cross-gender mentoring could also become a barrier to female trainee mentorship, as noted by a recent study of psychiatry residents [6]. For these reasons, women psychiatry residents are at risk for remaining isolated if they do not receive the assistance of their academic leaders in finding appropriate mentoring.

Fortunately, there are several ways that mentorship can be facilitated for women residents. Many residents begin mentoring relationships during a specific clinical rotation or during a defined research project. Examples of these so-called bottom up or functional mentoring activities include preparing a poster for research day or a grand rounds presentation [7], things that are required by most residency programs. I found my first mentor through a core clinical placement. During this rotation, my mentor allowed me to divide my time between research and clinical duties so that I could start a research project during working hours when my children were at daycare.

If the right chemistry exists between resident and supervisor, the relationship can continue beyond the initial project and may even lead to further collaboration. In my case, this research resulted in the publication of three papers. Having a mentor was an important first step in proving that it is possible to be a researcher, clinician, mother, and partner. I believe this could be the case for other women trainees who receive mentorship through functional mentoring activities. These smaller and more manageable projects provide an opportunity to connect women with influential mentors while providing an opportunity for academic achievement.

The residency program director can also be of assistance in facilitating mentorship for women residents. The program director has knowledge of both the organization and individual residents on a personal level. Simply protecting time in a female resident's busy schedule for meeting with a mentor is one of the ways programs can facilitate mentorship for residents during working hours. My program director was able to suggest individuals in the department whose interests aligned with my personal and professional goals, and she offered to help connect me with these people.

Equally essential in facilitating mentorship for all residents (but especially for women residents) is the "top down" approach. Academic leaders must promote the development of healthy, trusting relationships among all members of the department. Strong relationships will lead to greater collaboration and become a buffer in times of stress [8]. Ultimately, mentorship pairings are more likely to form if residents feel comfortable seeking guidance from senior members. Sponsorship of a formal mentoring program by academic leadership communicates to trainees that a "culture of caring" exists in their institution and also ensures that learners will be "set up" for success. Leadership support facilitated my connection with a senior faculty member who shares my interest in mentoring and education. This mentoring relationship has helped me to discover a new area of academic interest and lead to collaborations with those who are interested in education.

For many women mentees, the mentoring relationship is the first opportunity during medical training to discuss more than academic and clinical issues with a more senior faculty member. Through mentoring, women receive the wisdom of their mentors on how to manage work-life balance pressures [9]. My mentors provided me with a space to discuss combining an academic career with motherhood, and they provided solutions based on the wisdom of their experience and their own struggles. Having a forum to discuss work-life balance issues for the first time in my medical career has been invaluable in coping with the challenges of residency.

Department chairs, training directors, and other educators need to carefully consider how to develop mentorship programs for women residents. One size does not fit all. The challenges faced by women trainees necessitate that a thoughtful approach be taken to ensure all women have access to a mentoring relationship. However, I believe my experience is proof that mentoring is time well spent. It is a worthwhile activity that will enrich the residency experience for all residents.

As I reflect on my experiences as a female psychiatry resident, I am reminded of a quote I read recently which said, "Girls compete with each other, Women empower one another" [10]. This indeed reflects my own experiences with mentors. I am grateful for their time and talents. They have graciously allowed me to consider possibilities I never imagined. It is mentorship that has empowered me to form my own identity as a clinician, a researcher, and a mother.

Acknowledgments The author would like to acknowledge Drs. Ryan Van Lieshout, Priyanthy Weerasekera, and James Bourgeois for their assistance in the preparation of this manuscript.

\section{References}

1. Women in U.S. Academic Medicine Statistics and Medical School Benchmarking, 2011-2012. Washington, DC, Association of American Medical Colleges, 2012. Retrieved from: https://www. aamc.org/members/gwims/statistics/.

2. Levine RB, Fenny L, Kern DE, Wright SM, Carrese J. Stories from early-career women physicians who have left academic medicine: a qualitative study at a single institution. Acad Med. 2011;86(6):752-8.

3. Bogan AM, Safer DL. Women in psychiatric training. Acad Psychiatry. 2004;28(4):305-9.

4. Sambunjak D, Straus SE, Marusic A. Mentoring in academic medicine: a systematic review. JAMA. 2006;296(9):1103-15.

5. Buddeberg-Fischer B, Stamm M, Buddeberg C, Bauer G, Haemmig $\mathrm{O}$, Knecht $\mathrm{M}$, et al. The impact of gender and parenthood on physicians' careers - professional and personal situation seven years after 
graduation. BMC Health Serv Res. 2010;10:40. doi:10.1186/14726963-10-40.

6. Soklaridis S, Lopez J, Charach N, Broad K, Teshima J, Fefergrad M. Developing a mentorship program for psychiatry residents. Acad Psychiatry. 2014;38. doi:10.1007/s40596-014-0163-2.

7. Thorndyke LE, Gusic ME, Milner RJ. Functional mentoring: a practical approach with multilevel outcomes. J Contin Educ Health Prof. 2008;28(3):157-64.
8. Pololi L, Conrad P, Knight S, Carr P. A study of relational aspects of the culture of academic medicine. Acad Med. 2009;84:106-14.

9. Dutta R, Hawkes SL, Kuipers E, Guest D, Fear NT, Iversen AC. One year outcomes of a mentoring scheme for female academics: a pilot study at the Institute of Psychiatry, King's College London. BMC Med Educ. 2011;11:13. doi:10.1186/1472-6920-11-13.

10. Author unknown. Accessed from: www.pinterest.com/explore/ women-empowering-quotes/. 